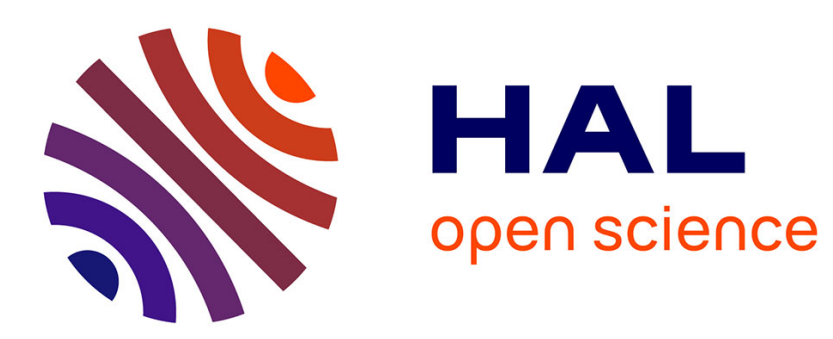

\title{
Ice accretion on wires and anti-icing induced by Joule effect
}

\author{
Pascal Personne, J.-F. Gayet
}

\section{To cite this version:}

Pascal Personne, J.-F. Gayet. Ice accretion on wires and anti-icing induced by Joule effect. Journal of Applied Meteorology, 1988. hal-01984558

\section{HAL Id: hal-01984558 \\ https://hal.uca.fr/hal-01984558}

Submitted on 3 Dec 2021

HAL is a multi-disciplinary open access archive for the deposit and dissemination of scientific research documents, whether they are published or not. The documents may come from teaching and research institutions in France or abroad, or from public or private research centers. publics ou privés.
L'archive ouverte pluridisciplinaire HAL, est destinée au dépôt et à la diffusion de documents scientifiques de niveau recherche, publiés ou non, émanant des établissements d'enseignement et de recherche français ou étrangers, des laboratoires

$$
\text { Copyright }
$$




\title{
Ice Accretion on Wires and Anti-Icing Induced by Joule Effect
}

\author{
P. PERSONNE AND J.-F. GAYET \\ L.A.M.P., Université de Clermont II, Laboratoire Associé au CNRS $n^{\circ} 267$, France
}

(Manuscript received I February 1986, in final form 15 August 1987)

\begin{abstract}
This study concerns both the formation of ice accreted around wires due to rotation from gravitational and aerodynamic forces, and the anti-icing induced by the Joule effect. The experiments have been carried out in an instrumented wind tunnel operating in natural conditions. The results show that the growth rate increases with the ice deposit thickness. Because of low airspeed and small cloud droplets, the total collection efficiency is less than 0.2 . The discrepancies between the observed collection efficiencies and those predicted by Langmuir and Blodgett's theory increase with time and consequently with the ice thickness. This may be due to the complex shape of the deposit which is noncircular and presents a rough surface. These results point out the difficulties in modeling the detail of such ice profiles in this range of conditions. The air temperature plays a significant role in the rotation angle of the wire and in the ice growth rates. The surface temperature of wires is measured in order to validate the heat balance of the heated wires; this gives a proposed estimation of the current to prevent the wire from icing.
\end{abstract}

\section{Introduction}

Power lines are sometimes damaged by atmospheric ice accretion caused by cloud and fog riming if the combined ice and wind effects exceed the design loads of the structure of the lines. Considerable work, mostly devoted to describing theoretically the intensity of icing on structures (Imai, 1953; Ackley and Templeton, 1979; McComber and Touzot, 1981; Lozowski et al., 1983; Makkonen, 1984) has already been done on the subject. Until now, these theoretical studies have generally been compared with observations obtained from laboratory wind tunnel experiments (Makkonen and Stallabrass, 1984). Nevertheless, the lack of experimental data (collected in natural icing conditions) concerning the relevant atmospheric parameters seriously hampers the development of the modeling of the icing process.

In mountainous regions of France, and above 700 $\mathrm{m}$ MSL elevation, the power lines are specially designed to support overloading by ice accretion and wind effects. Since this reinforcement of the structure significantly increases the construction cost of the power lines, the low altitude network is not protected against these atmospheric conditions. The atmospheric icing of power line networks located in nonmountainous areas is generally observed during winter anticyclonic situations with supercooled fog or low stratus clouds, and at low wind speeds $\left(<10 \mathrm{~m} \mathrm{~s}^{-1}\right)$ (Gland, personal communication, 1986). The damages attributed to

Corresponding author address: Dr. J.-F. Gayet, LAMP, Université de Clermont II, B.P. 45, 63170 Aubiere, France. these conditions during the 1973-83 period has been listed by Gland (1985). This author also shows that the icing situations are characterized by a temperature ranging mostly from $0^{\circ}$ to $-5^{\circ} \mathrm{C}$ and that the icing episodes can last several days.

The first purpose of this paper is to describe experimental studies of the formation of ice on wires in an instrumented wind tunnel operating in natural conditions. The second purpose is to present preliminary results on the prevention of the icing of wires by Joule heating.

\section{Description of the experimental procedure}

\section{a. The wind tunnel}

The instrumented horizontal wind tunnel is set up at the Observatory of Puy de Dôme which is located at the summit of Puy de Dôme Mountain (1465-m MSL). Figure 1 displays a sketch of the wind tunnel. Inside a first sampling section of $46.8 \times 64.8 \mathrm{~cm}$, two model wires are installed while in a second sampling section (situated downstream) of $23.4 \times 32.4 \mathrm{~cm}$, the microphysical and dynamical probes are set up. The airspeed can vary from 5 to $15 \mathrm{~m} \mathrm{~s}^{-1}$ in the first sampling section and from 20 to $60 \mathrm{~m} \mathrm{~s}^{-1}$ in the second one by adjusting the power supply of the motor. The convergent entry bell located outside the observatory (Fig. 1) has an area of $153 \times 159 \mathrm{~cm}$, and ensures a contraction ratio of 8 between the plenum and the first sampling section. Furthermore, the convergent bell mouth contains a grid extended by adjustable flaps in order to improve the homogeneity of the sampled clouds when the outside wind is not directed along the 


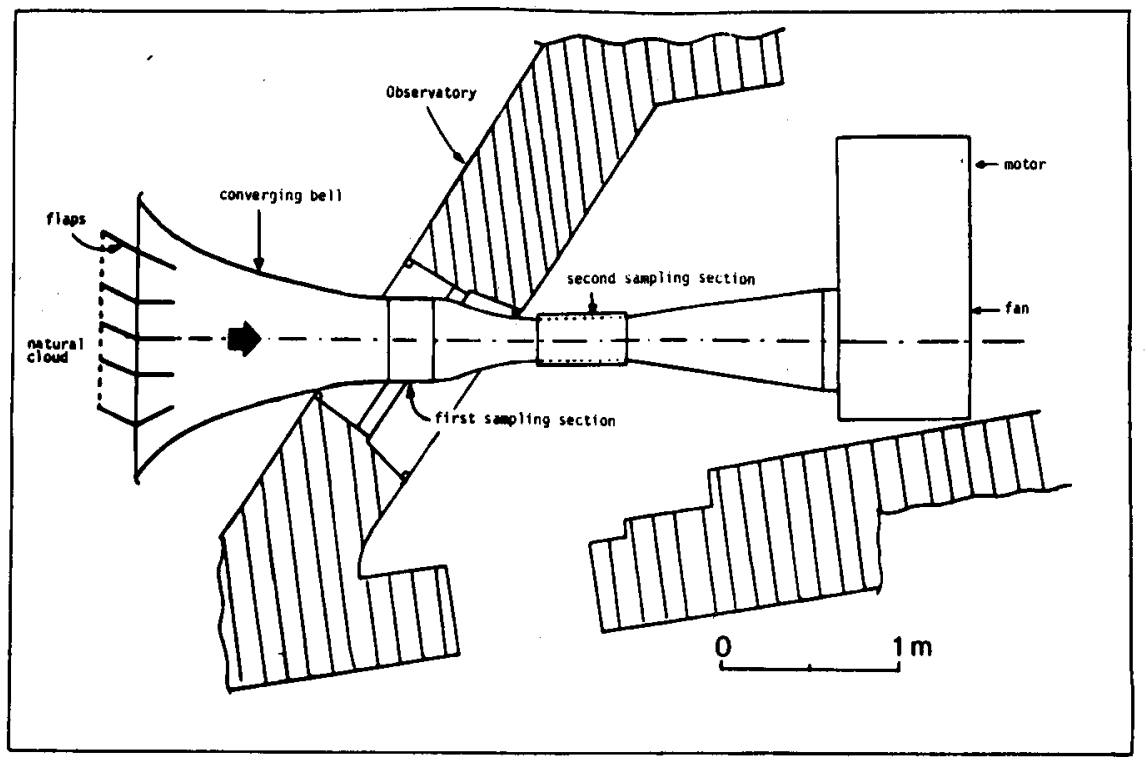

FIG. 1. Sketch of the wind tunnel set up on the summit of Puy de Dôme Mountain.

wind tunnel axis. For the largest ice profiles obtained during the experiment (appendix A), the maximum tunnel blockage ratio was only $9 \%$ (except for test 8 where it was $20 \%$ ). According to the experimental procedure and results reported by Makkonen and Stallabrass (1984), the tunnel blockage effects may not have a significant effect on droplet trajectories.

\section{b. Instrumentation}

\section{1) Meteorological MEASUREMENTS} ing:

The probes and mounting locations are the follow-

- A PMS ${ }^{1}$ ASSP for the measurement of cloud droplet spectra with diameter ranging from 3 to 45 $\mu \mathrm{m}$.

- A PMS 1D-C for the measurement of particles ranging from 20 to $300 \mu \mathrm{m}$. This probe was modified to have only the arms inside the sampling section.

- A Pitot tube for the measurement of the tunnel airspeed.

These probes are set up in the second sampling section as shown on Fig. 2.

The aforementioned instrumentation is complemented by a reverse-flow temperature probe and a Cambridge dewpoint sensor installed in the first sam-

\footnotetext{
${ }^{1}$ Particle Measuring Systems, Boulder, Colorado.
}

pling section, and two platinum resistance thermometers giving the outside air temperature.

\section{2) WIRES}

One or two model wires (Aster 148 and Aster 570), $50 \mathrm{~cm}$ long, are set up in the first sampling section. In order to simulate the rotation of the wires under the influence of the ice accretion, the model wires are set up in conical bearings on the tunnel walls and are attached to a helical spring (Fig. 3) giving a constant torsion couple such that the model wire simulates the midpoint of a typical transmission span (100 and 260 $\mathrm{m}$ for the Aster 148 and the Aster 570, respectively). Furthermore, these two model wires have a core consisting of a steel cylinder inside which heating resistors (resistance respectively 300.6 and $238.1 \Omega$ in Aster 148 and Aster 570) are introduced to simulate the heating of the wire by Joule effect. A small surface temperature probe (platinum resistor of $2.0 \times 2.3 \mathrm{~mm}$ ) is put on the surface of the two model wires.

The characteristics of the two model wires are the following:

- Aster 148: Constructed by wrapping 12 strands of $3.5 \mathrm{~mm}$ diameter aluminum wire, giving an overall diameter of $1.57 \mathrm{~cm}$. Its torsional resistance is supplied by a spring having a spring constant of $4.52 \times 10^{-3}$ $\mathrm{nm} / \mathrm{rad}$. The electrical resistance $(\mu)$ per unit length is $0.2089 \Omega \mathrm{km}^{-1}$ at $0^{\circ} \mathrm{C}$.

- Aster 570: Constructed by wrapping 24 strands of $3.5 \mathrm{~mm}$ diameter aluminum wire, leading to an overall 


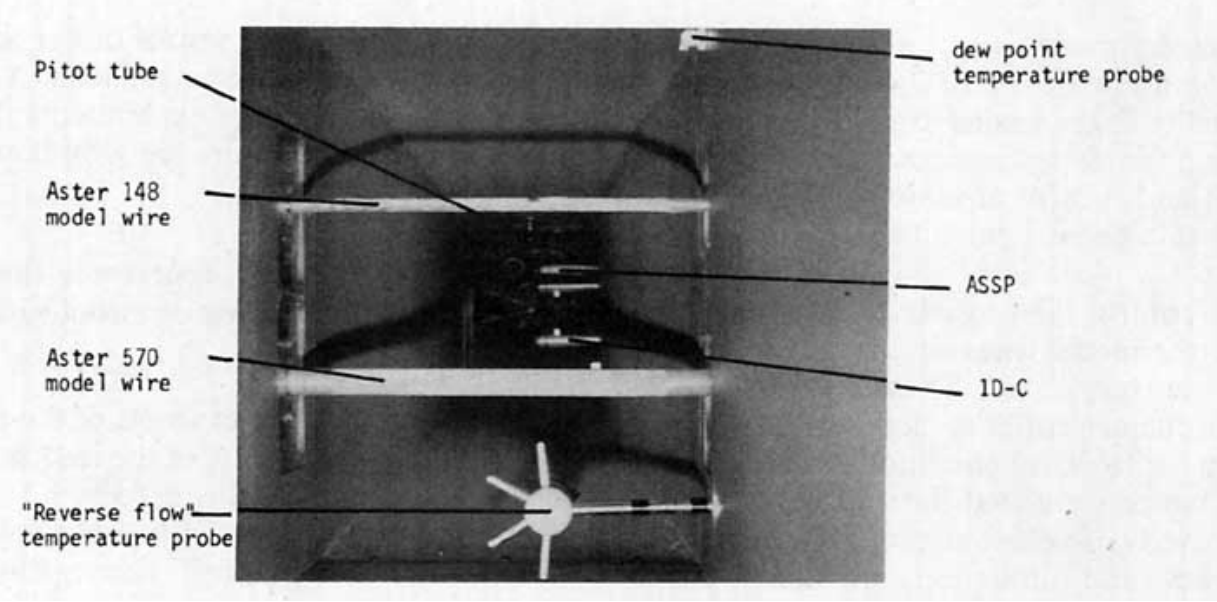

FIG. 2. Mounting locations of the two model wires, and microphysical, dynamical, and temperature probes.

diameter of $3.10 \mathrm{~cm}$. The spring constant is 9.58 $\times 10^{-3} \mathrm{~nm} / \mathrm{rad}$. The electrical resistance per unit length is $0.05438 \Omega \mathrm{km}^{-1}$ at $0^{\circ} \mathrm{C}$.

\section{3) COMPlementary Devices}

The microphysical, dynamical, and temperature measurements are displayed in real time and recorded at $0.1 \mathrm{~Hz}$ on magnetic tapes. In the observatory a microcomputer is used to calculate and to graphically display the parameters after each test. During the test, the ice growth and the model wire rotation are monitored with $8 \mathrm{~mm}$ and video cameras. This instrumentation is sup- plemented by an accurate balance used to weigh the ice deposits.

\section{4) ACCURACIES OF THE MEASUREMENTS}

The homogeneity of the instrumented sampling sections has been controlled by two methods. For the first, local airspeed measurements were performed across the section with a small Pitot tube. The results show that, for a fixed airflow, the variations of the airspeed is less than $5 \%$ and that the boundary layer near the walls is less than $1 \mathrm{~cm}$ thick at $40 \mathrm{~m} \mathrm{~s}^{-1}$. The second method was to visually check the homogeneity of the

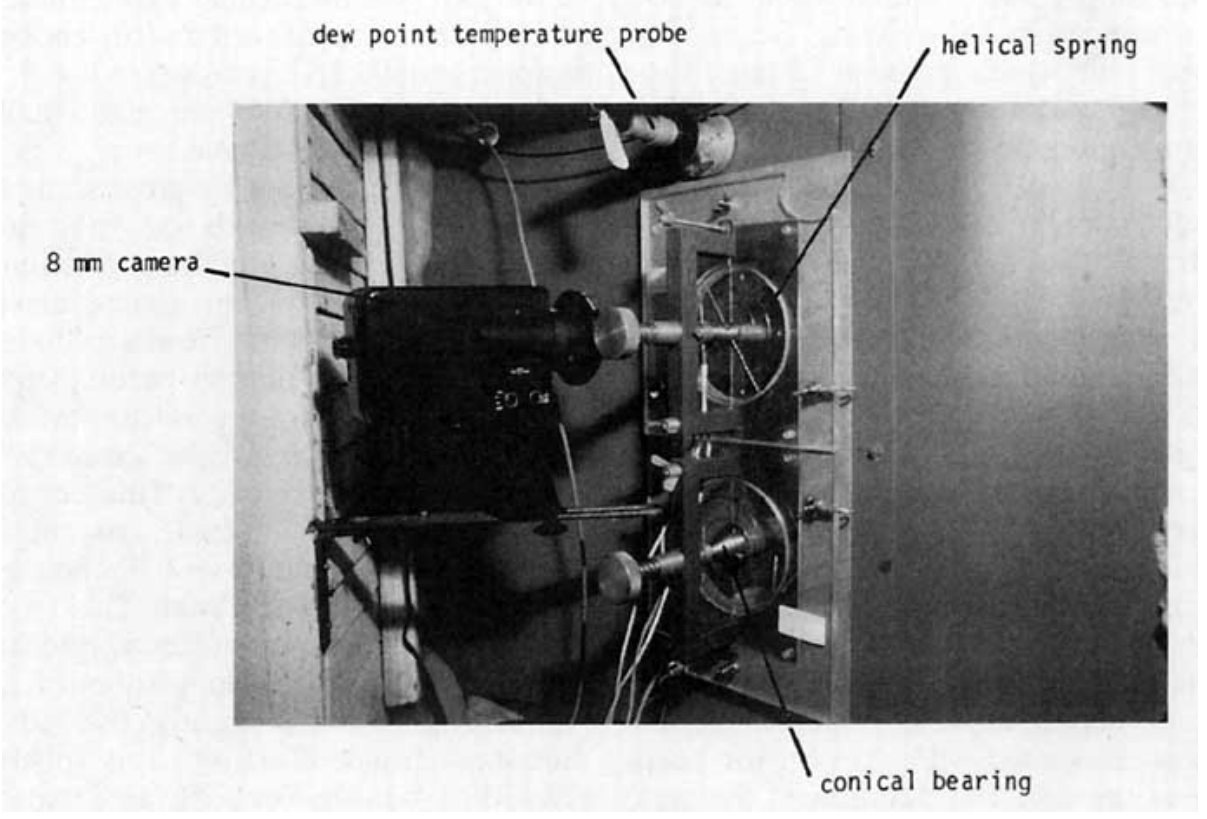

Fig. 3. Instrumentation of the two model wires. 
ice deposits on the model wires in the first sampling section, and on a P.V.C. rod of $2.2 \mathrm{~cm}$ diameter occasionally installed in the second sampling section. The results show that the ice deposits are very homogeneous on both wires and rods in any meteorological situations except within about $1 \mathrm{~cm}$ of the walls of the wind tunnel.

In order to control the possible shadow effects on the probes by the model wires situated upstream, additional tests were carried out. These tests consisted of measuring the characteristics of cloud droplets during quasi-stable meteorological conditions with and without obstacles which simulated the iced wires. The results showed a negligible effect on probe measurements.

The accuracy and limitations of microphysical probes were discussed in detail by Gayet (1986). From calibrated wind tunnel experiments the author shows that the ASSP liquid water content can be estimated with about $30 \%$ accuracy. According to the results of Dye and Baumgardner (1984), the sizing accuracy is limited by inhomogeneities in the laser beam, ambiguities in the Mie scattering curves and by the airspeed. For the low airspeed used during the experiment $(\sim 40$ $\mathrm{m} \mathrm{s}^{-1}$ ), the standard deviation of the cloud droplet diameter measurements (therefore on the median volume diameter) could be evaluated at $3 \mu \mathrm{m}$. Furthermore, the ASSP calibrations performed during the icing experiment showed a very repeatable probe response. Good agreement is found between the four temperature measurements (the deviations between the different probes were less than $0.5^{\circ} \mathrm{C}$ ).

\section{c. Experimental procedures}

The open wind tunnel was operated when the observatory was surrounded by icing clouds. During the whole 1985 experiment, which included 18 tests, various meteorological conditions were observed. The outside mean temperature was most commonly $-4^{\circ} \mathrm{C}$ but ranged from $-17^{\circ}$ to $0^{\circ} \mathrm{C}$; the mean values of the cloud liquid water content and median volume diameter ranged from 0.1 to $0.6 \mathrm{~g} \mathrm{~m}^{-3}$, and from 7 to $16 \mu \mathrm{m}$, respectively.

Two series of experiments were carried out during the winter 1984/85 campaign. For the first one, the icing growth was studied on the two rotating and nonheated model wires. During these tests, the angles of rotation of the two model wires were measured approximately every $15 \mathrm{~min}$, and the ice deposits were weighed and photographed approximately every $2 \mathrm{~h}$ (depending on the icing intensity) during a short interruption of the airflow in the wind tunnel. The tests were stopped when the icing situation vanished or when the air temperature changed noticeably due to a sudden change of airmass associated with a warm (or cold) front moving over the site. The duration of the tests varied from 2 to 22 hours, but was usually 10 hours.
The characteristics and results of the tests performed in 1985 are summarized in appendix A.

In the second series of experiments the current required to prevent the wire icing by heating was evaluated.

\section{Experimental results concerning the icing of free- rotating and non-heated model wires}

\section{a. Detailed description of a typical test}

Figure 4 displays an example of the time evolution of the angle of rotation $\theta$, of the ice load $M$ measured on the Aster 148 model wire $(\phi=1.57 \mathrm{~cm})$, airspeed $V$, liquid water content $W$, median volume diameter MVD and air temperature $T$. During this test, the mean air temperature was $-16^{\circ} \mathrm{C}$. The test lasted $7 \mathrm{~h} 30 \mathrm{~min}$ during which the liquid water content and the median volume diameter had slow time fluctuations which ranged from 0.2 to $0.6 \mathrm{~g} \mathrm{~m}^{-3}$ and from 10 to $18 \mu \mathrm{m}$, respectively. Nineteen measurements of angle of rotation and four of ice deposit weight were performed during this test. These weight measurements define four periods labeled I to IV on Fig. 4. The mean liquid water content is reported on the figure for these four periods. At the end of the test, the ice load reached 147 $\mathrm{g}$ for an ice deposit of $44 \mathrm{~cm}$ long on the model wire, and the final angle of rotation was $291^{\circ}$. The progressive icing of the wind tunnel walls induced a slow decrease of the airspeed in the working sections (Fig. 4). In order to ensure a quasi-constant value of the airflow, two de-icing operations were carried out at 0220 LST and 0445 LST. This causes an airspeed rise of about 2 $\mathrm{m} \mathrm{s}^{-1}$ and consequently a sharp increase of the angle of rotation of about $25^{\circ}$, due to the wind pressure effect on the non symmetric quasi-flat surface of the ice deposit. An example of such an ice deposit cross section sampled at 0603 LST is shown in Fig. 5, and is similar to those obtained by Makkonen and Stallabrass (1984) in a laboratory wind tunnel.

Figure 6 displays the ice cross sections obtained at the end of the four periods (drawn from photographs) and the corresponding angles of rotation of the model wire. This figure shows that, as time increases, ice shape deviates more and more from a cylinder and the appearance of the ice deposit becomes rougher. At the end of the test, the front surface is rather flat by comparison with the near circular shape of the rear of the profile. The center of gravity of the ice profile is situated about $6 \mathrm{~mm}$ below the cable axis, the final profile is not symmetric (axis ratio $\sim 0.8$ ) and the approximate height of roughness is $3 \mathrm{~mm}$. This type of ice shape was observed during all the tests performed during the experiment, even for the longest one of 2220 LST. This type of ice deposit was recently observed on power lines during an episode of natural atmospheric icing which lasted 3 days in the Grenoble area (Admirat, personal communication, 1985). 


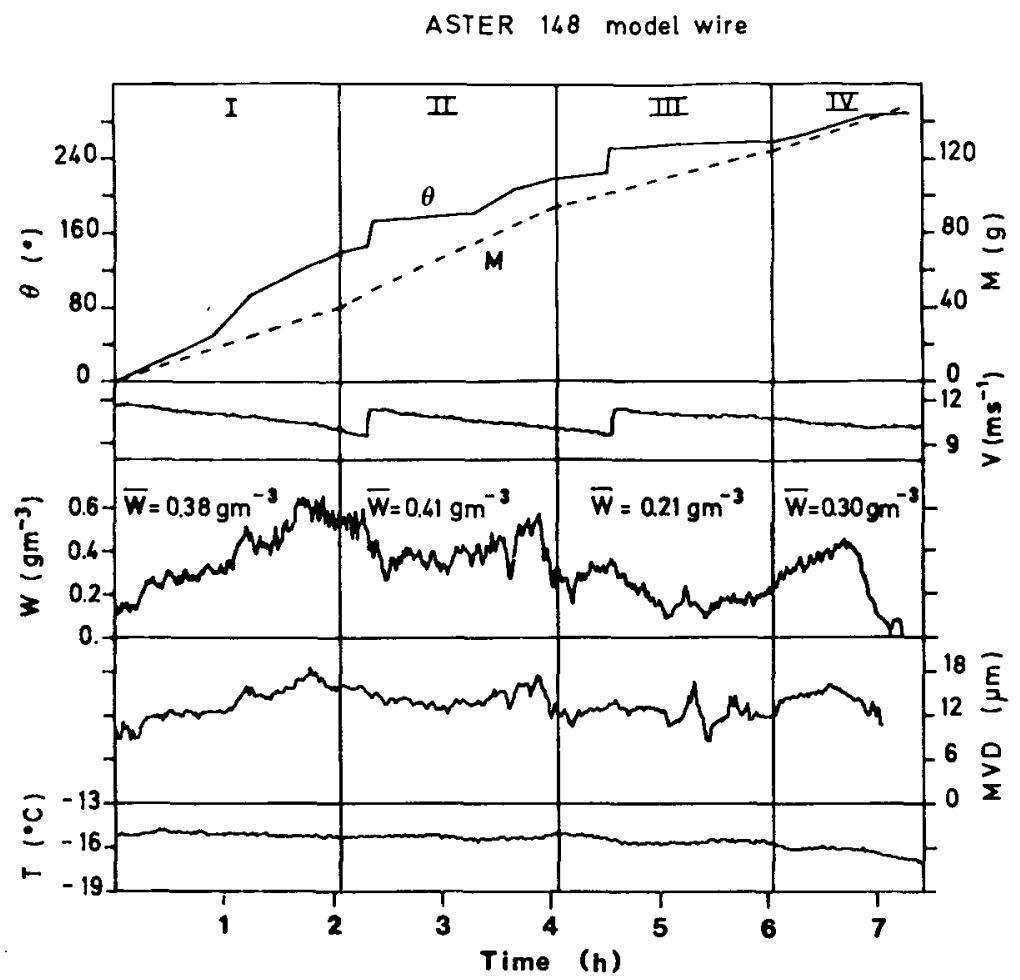

FIG. 4. Time evolution of the angle of rotation $\theta$ and ice load $M$ measured on the Aster 148 model wire; airspeed $V$, liquid water content $W$, median volume diameter MVD and air temperature $T$. This test is split into four periods labeled I to IV (test $15)$.

\section{b. Mass growth rate versus liquid water content}

Figures $7 \mathrm{a}$ and $7 \mathrm{~b}$ show, for the Aster 148 and Aster 570 model wires respectively, the mass growth rates obtained from the weight measurements versus the mean liquid water contents. The calculation of the regression lines (also indicated on Figs. $7 \mathrm{a}, \mathrm{b}$ ) shows that the slopes are quite similar for the two model wires

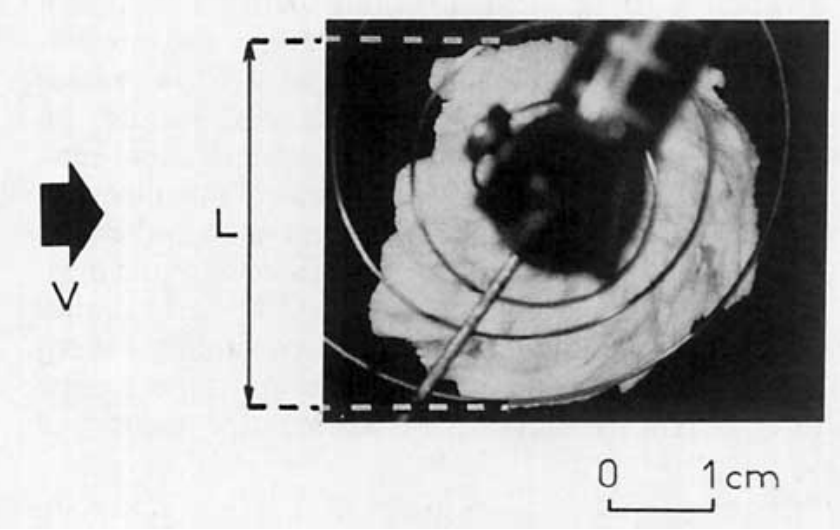

FIG. 5. Cross section of the ice deposit photographed at the end of Part III (see Fig. 4). The ice front width is labeled $L$.
(129.3 and $127.6 \mathrm{~m}^{2} \mathrm{~h}^{-1}$ ) despite different initial diameters. This result corroborates the observations previously discussed by Personne and Gayet (1984) concerning the icing of fixed wires.

On the other hand, the correlation coefficients are only 0.76 and 0.81 due to the scattered values of the measurement points. There may be several reasons for this dispersion: the measurement uncertainties, (estimated at less than $30 \%$ from the probe accuracies) and the effects on the mass growth rate of the uncontrolled variations of the pertinent parameters such as the median volume diameter, the temperature and the time increase of the ice deposit thickness. These effects are discussed in subsections $3 \mathrm{c}$ and $3 \mathrm{~d}$.

\section{c. Effect of the width of the ice front surface on the mass growth rate and on the total collection effi- ciencies}

The increase of the ice deposit thickness as a function of time leads to a significant increase of the mass growth rate. For example, the measurement points labeled $\mathrm{A}$ and $B$ on Fig. 7a have been obtained $2 \mathrm{~h}$ and $18 \mathrm{~h}$, respectively, after the beginning of test 27 (see also appendix A), and are characterized by a similar liquid water content $\left(0.4 \mathrm{~g} \mathrm{~m}^{-3}\right)$ and median volume diameter 


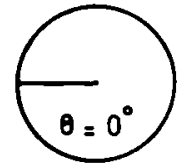

to

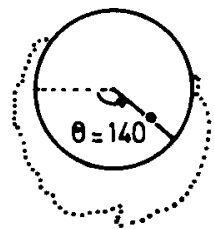

$t_{1}=t_{0}+2 h 05$
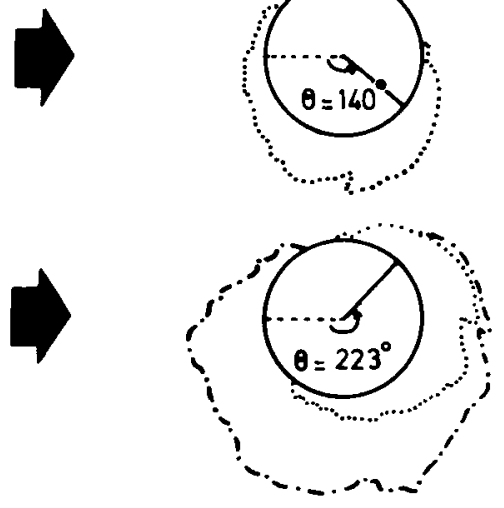

$t_{2}=t_{1}+2 h \infty$

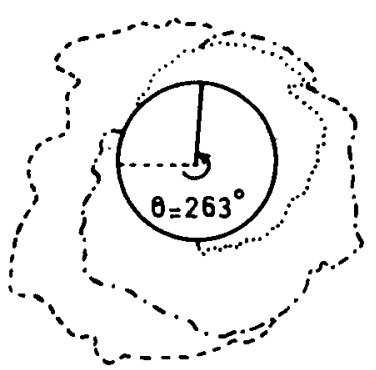

$t_{3}=t_{2}+\ln 58$
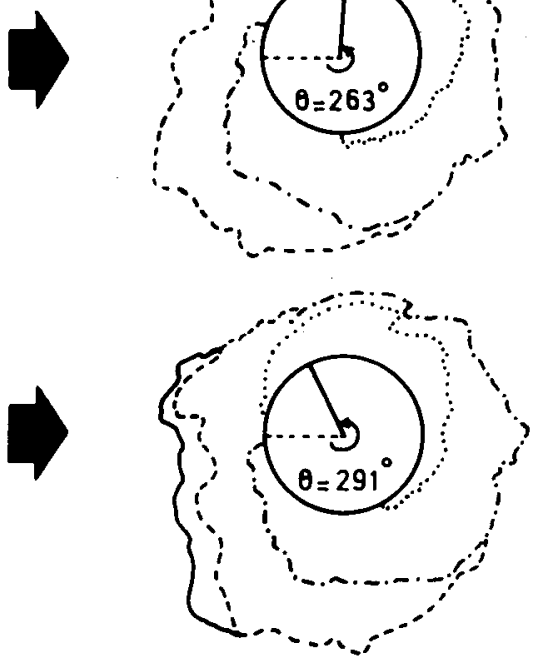

$t_{4}=t_{3}+\ln 21$

Fig. 6. Sequential ice cross sections obtained during the test described in Fig. 4 (Aster 148 model wire, $\phi=1.57 \mathrm{~cm}$ ). The corresponding sampling times and angles of rotation of the wire are indicated. The wind vector is also reported.

$(12.5 \mu \mathrm{m})$. The mass growth rate and ice front width ${ }^{2}$ of the $A$ and $B$ points are, respectively, $33.4 \mathrm{~g} \mathrm{~m}^{-1} \mathrm{~h}^{-1}$ and $1.65 \mathrm{~cm}$ compared to $96.5 \mathrm{~g} \mathrm{~m}^{-1} \mathrm{~h}^{-1}$ (about three times larger) and $5.5 \mathrm{~cm}$.

To exemplify more precisely this result, we now consider the ratio of the mass growth rate to the air-

\footnotetext{
${ }^{2}$ Due to the roughness of the surface and the nonsymmetrical profile of the ice deposit observed during all the tests, we cannot speak of ice deposit diameter. Consequently, we define the ice front width as the total width of the ice profile situated perpendicularly to the wind vector (Fig. 5).
}

speed and the liquid water content. From the formulation of the mass growth rate, this ratio can be written as

$$
R /(V W)=E_{p} L,
$$

where $R$ is the mass growth rate $\left(\mathrm{g} \mathrm{m}^{-1} \mathrm{~h}^{-1}\right), V$ the airspeed $\left(\mathrm{m} \mathrm{s}^{-1}\right), W$ the liquid water content $\left(\mathrm{g} \mathrm{m}^{-3}\right)$, $E_{p}$ the total net collection efficiency (all the cases are above the Ludlam limit, i.e., in dry growth) and $L(\mathrm{~m})$ the ice profile front width (average over the interval in which $R$ is measured).

Figure 8 displays the values of the above ratio (obtained from the measured parameters) against the ice front width for the two model wires (triangles and circles). This figure shows that the $R /(V W)$ values for the Aster 570 wire are quite similar to those of the Aster 148 wire in the corresponding range of the ice front width. Furthermore, these experimental results show that the $R /(V W)$ ratio and $L$ are distributed closely about a straight line. Consequently, for an ice front width ranging from 1.7 to $5.7 \mathrm{~cm}$, the total collection efficiencies defined in (1) are nearly constant (from 0.15 to 0.10 ), as shown on Fig. 9, in regard to the evolution of the theoretical cylinder collection efficiencies (solid curve on Fig. 9) decreasing from 0.15 to 0.03 in the same range of diameter. These theoretical coefficients are based on the numerical solution of Langmuir and Blodgett (1946) and corrected as suggested by Makkonen (1984). They are obtained using the mean values of the measured median volume diameter $(12 \mu \mathrm{m})$ and airspeed $\left(10 \mathrm{~m} \mathrm{~s}^{-1}\right)$. It should be noted that only the measurement points labeled $\mathrm{B}$ and $\mathrm{C}$ may be affected by the history term (Crowe et al., 1963), which is not taken into account in the Langmuir and Blodgett's theory.

Nevertheless, the comparisons with theory must be considered as qualitative due to the complex shapes of the observed ice deposits, and to the errors inherent to the experiment procedure with uncontrollable icing conditions.

Despite these restrictions it should be noticed that a variation of the median volume diameter induces a lower experimental deviation of the collection efficiency than predicted by the theory relative to a smooth cylinder. For example, the points labeled $\mathrm{B}$ and $\mathrm{C}$ on Figs. 8 and 9 were obtained during relative stable icing conditions characterized by a median volume diameter of 12.4 and $7.9 \mu \mathrm{m}$ respectively (with standard deviations of only $1 \mu \mathrm{m}$ during the time interval of the measurement), the same temperature $\left(-3^{\circ} \mathrm{C}\right)$ and a similar front width $^{3}(\sim 5.5 \mathrm{~cm})$. The corresponding experimental total collection efficiencies are quite similar (0.11 and 0.10, see Fig. 9), whereas the theoretical

\footnotetext{
${ }^{3}$ For such a large value of the front width the error margin on this parameter is weak $(\sim 5 \%)$.
} 
ASTER 148

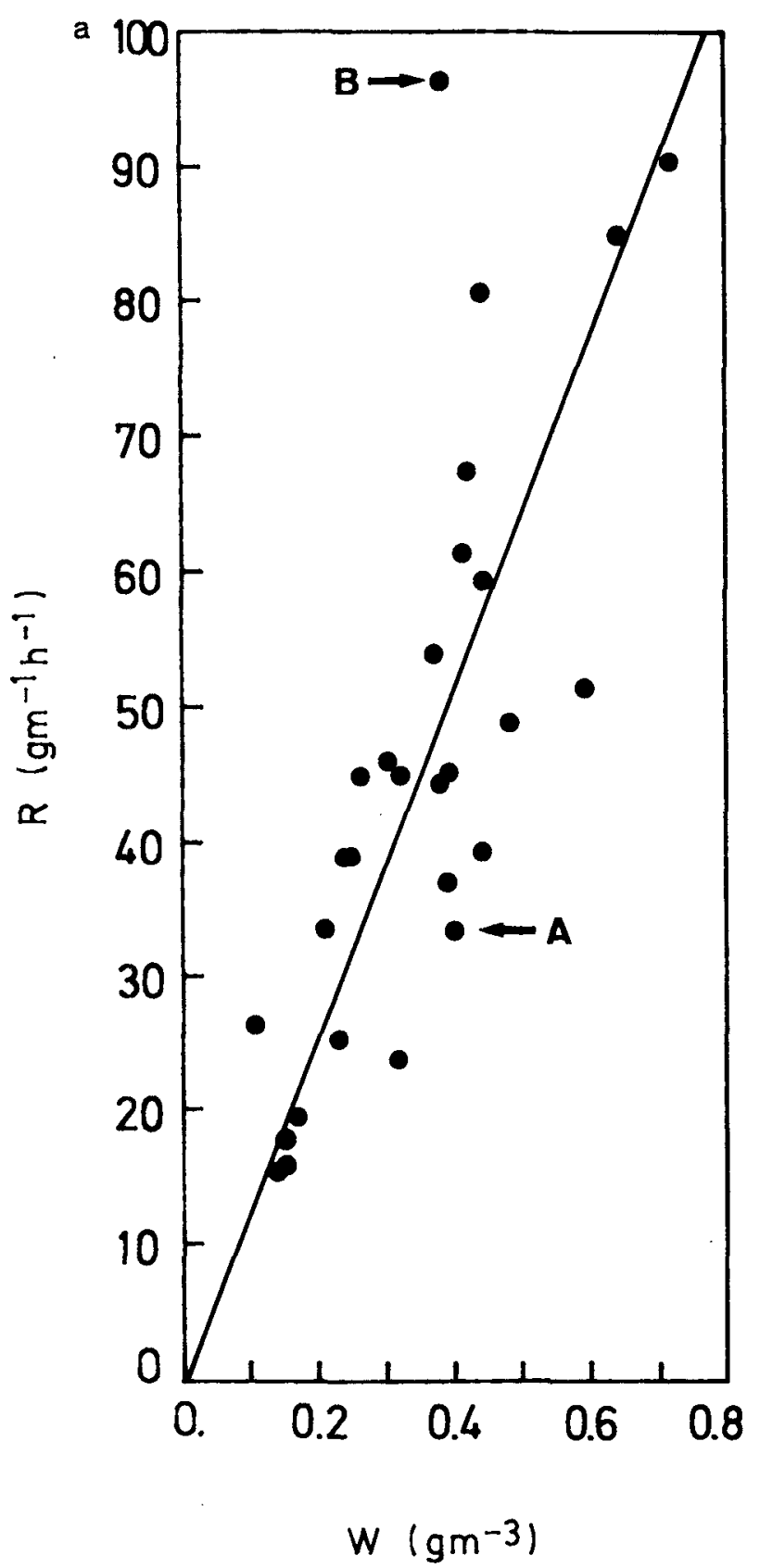

ASTER 570

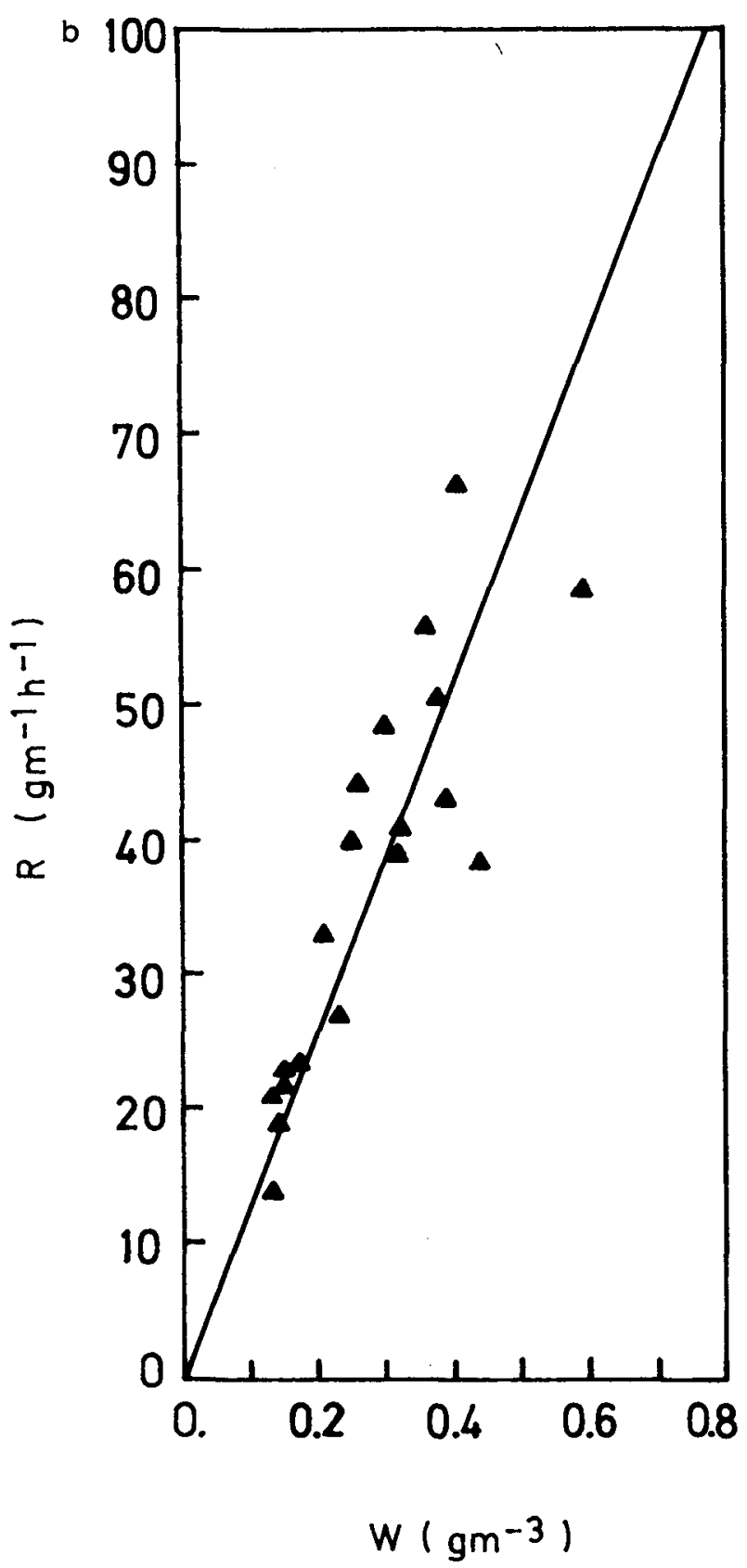

FIG. 7. Mass growth rate $R$ as a function of the liquid water content $W$. (a) Aster 148 model wire $(\phi=1.57 \mathrm{~cm})(\mathrm{b})$ Aster 570 model wire $(\phi=3.10 \mathrm{~cm})$.

smooth cylinder collection efficiencies are, respectively, 0.053 and 0.007 .

The representation of the theoretical product $(E D)$ (with $D$ the cylinder diameter) on Fig. 8 (solid curve) exemplify an opposite tendency of the variations of the experimental and theoretical values as a function of $L$ (or $D$ ) for an ice front width larger than $2 \mathrm{~cm}$. This suggests that during natural conditions and for small values of the total collection efficiencies, the mass growth rate increases with the ice front width (therefore with time), unlike the prediction by the theory, for ice width larger than $2 \mathrm{~cm}$. This result confirms the ob- 


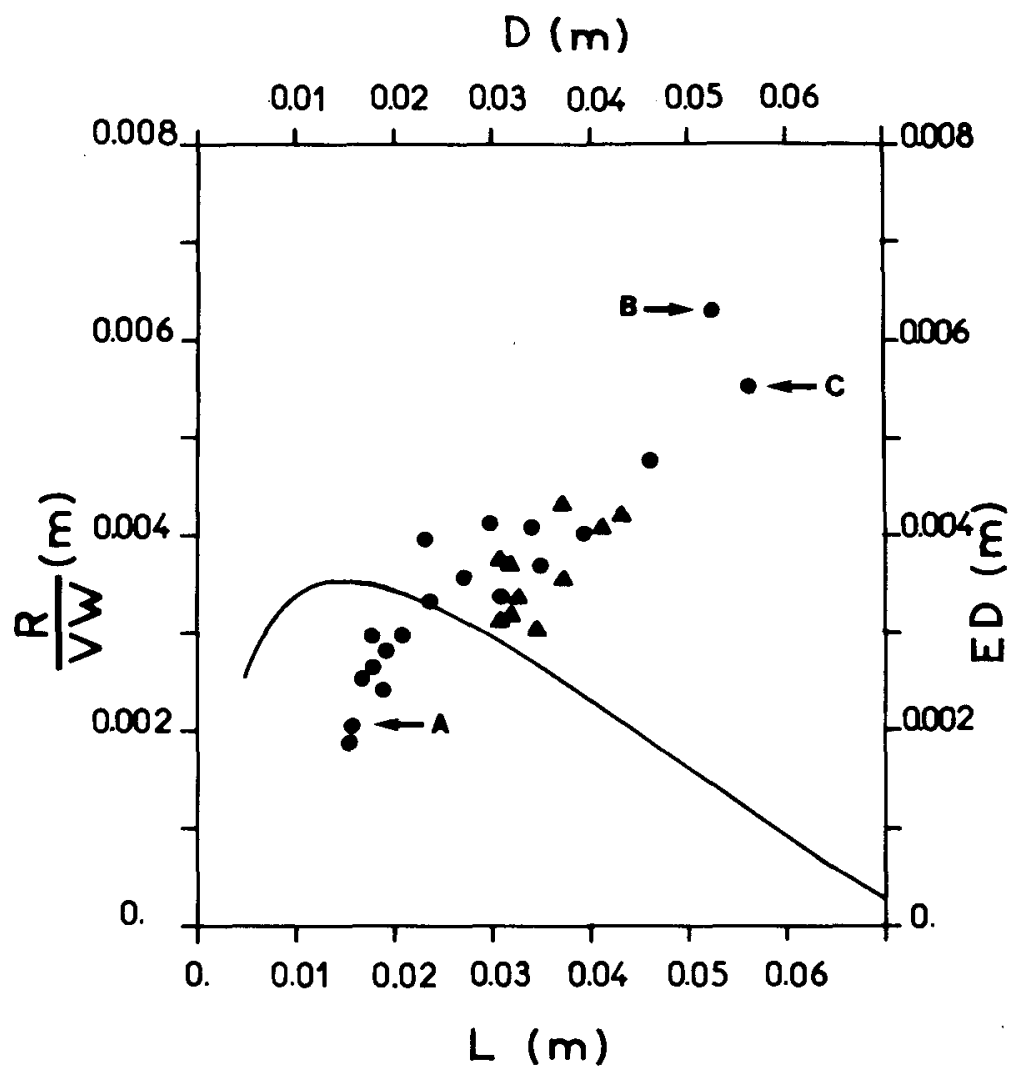

FIG. 8. Mass growth rate per unit of airspeed and liquid water content, $R /(V W)$, as a function of the ice front width $L$. Solid circle symbols refer to the Aster 148 model wire, and solid triangle to the Aster 570 model wire. The solid curve is the theoretical relationship between the diameter of a cylinder $D$ and the product of this diameter by the calculated total cylinder collection efficiency coefficients ED (scale on the right).

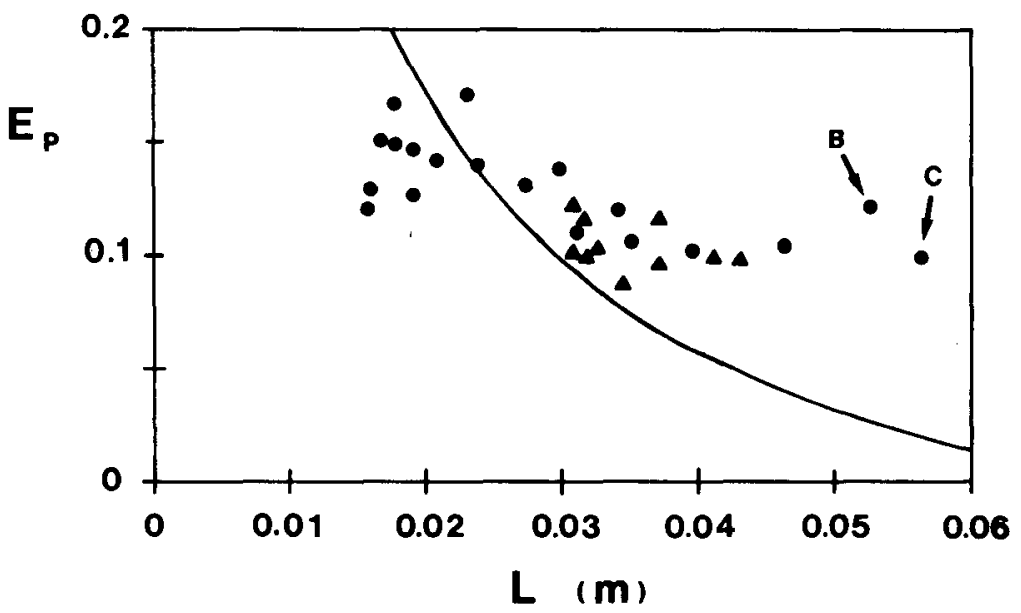

FIG. 9. Measured total collection efficiencies as a function of the ice front width $L$. Solid circles refer to the Aster 148 model wire, and solid triangle refer to the Aster 570 model wire. The solid curve is the theoretical relationship between the total collection efficiency of a smooth cylinder and the diameter $L$. 
servations of McComber and Govoni (1985) obtained from natural wire icing experiment.

The discrepancies between the experimental and theoretical results may be explained by the low speed of the droplets and the test duration which induce an ice shape which progressively deviates from a cylinder and a surface which becomes progressively rougher. As a matter of fact, for low speeds of the droplets, the initial places of deposition become favored regions of growth due to a local increase in the efficiency of capture (Macklin, 1962; Brownscombe and Hallet, 1967). As for the vapor deposition on the lee side of the deposit, visual observations showed that the ice surface never presented needle or dentrite crystal shapes which are typical of such phenomenon.

These observations point out the difficulties in modeling the details of the small collection efficiencies relative to the rough and complex shapes of the ice deposits as suggested by Makkonen (1984), and further investigations are needed to specify more precisely the values of the collection efficiencies for a larger range of conditions.

\section{d. Influence of the air temperature on the angle of ro- tation of the wire and mass growth rate}

Figure 10 displays the time evolution of the angle of rotation of the wire obtained during three icing tests on the Aster 148 model wire $(\phi=1.57 \mathrm{~cm})$. These tests were conducted with similar airspeed $\left(V \sim 10.5 \mathrm{~m} \mathrm{~s}^{-1}\right)$ and liquid water content $\left(W \sim 0.35 \mathrm{~g} \mathrm{~m}^{-3}\right)$ but with different air temperatures: $-1.5^{\circ},-5.4^{\circ}$, and $-16.1^{\circ} \mathrm{C}$. The corresponding ice densities $(\rho)$ which were measured are also reported in Fig. 10. The three curves show sharp increases due to the above-mentioned operation of de-icing of the wind tunnel performed $2 \mathrm{~h}$ $30 \mathrm{~min}$ after the beginning of the tests. This figure clearly shows that the angle of rotation becomes the greater as the temperature is reduced. Consequently, at $-1.5^{\circ} \mathrm{C}$ the rotation rate is about $29 \mathrm{deg} \mathrm{h}^{-1}$ and twice this $\left(60 \mathrm{deg} \mathrm{h}^{-1}\right)$ at $-16.1^{\circ} \mathrm{C}$. This dependence could be explained by the following observations:

i) Firstly, as shown on Fig. 10, the lower the temperature the smaller the ice density. This corroborates the results of Macklin (1962).

ii) Secondly, for the same water mass flux impinging on the wire, the lower the ice density, the larger the ice thickness (or ice front width) and, consequently, the greater the mass growth rate (see Fig. 8). Indeed, the corresponding measured mass growth rates are 25 and $47 \mathrm{~g} \mathrm{~m}^{-1} \mathrm{~h}^{-1}$ for temperatures of -1.5 (Fig. 10, dotted curve) and $-16.1^{\circ} \mathrm{C}$ (dashed curve), respectively.

Consequently, the angle of rotation and mass growth rate are significantly enhanced when the air temperature is decreased. In effect, both the moment arm and the ice weight increase due to the augmentation of the ice thickness itself which is controlled by the ice density.

\section{Experimental results concerning the anti-icing of the wires by heating}

\section{a. Description of the procedure and results}

This experiment aimed to evaluate the current required to prevent the icing of the wire by heating. At the beginning of these tests, the wire surface temperature was set to $0^{\circ} \mathrm{C}$ by adjusting the electric power of the inside heating resistors. This electric power was maintained at a constant value during the test in spite of the possible variations of the icing situation.

Figure 11 gives an example of such a test by heating the Aster 148 wire. The liquid water content, the air temperature, the wire surface temperature measured at the stagnation line and the airspeed are plotted as a function of time. During this test, the air temperature and the airspeed remain constant $\left(-2.5^{\circ} \mathrm{C}\right.$ and $12 \mathrm{~m}$ $\mathrm{s}^{-1}$ ) and the wire surface temperature is positive (due to an equivalent current intensity of $425 \mathrm{~A}$ ) but fluctuates between 0.5 and $2^{\circ} \mathrm{C}$. Figure 11 shows that these fluctuations are anti-correlated with the liquid water content. For example, an increase of $0.15 \mathrm{~g} \mathrm{~m}^{-3}$ induces a decrease of the surface temperature of about $1^{\circ} \mathrm{C}$. This shows that the wire cooling due to the evaporation of the impinging water droplets and also the heat loss in warming the impinging water to the surface temperature play a significant role in the heat balance of the wire. Consequently, the estimation of the current required to prevent the icing of the wire in any conditions, needs a particular formulation of the heat balance. This proposed formulation (discussed in subsection $4 \mathrm{~b}$ and appendix B) will be confirmed by comparison between the calculated and measured wire surface temperatures.

\section{b. Calculation of the wire surface temperature}

The wire surface temperature can be calculated from the heat balance of the heated (noniced) wire. Due to the high conductivity of the wire, the temperature obtained on the stagnation line represents the surface temperature over the forward half of the wire. This was confirmed by specific surface temperature measurements at different angles around the model wire (noniced). The results show no significant temperature variations with regard to the probe accuracy $\left(0.5^{\circ} \mathrm{C}\right)$. Accordingly, the equation of the surface temperature is

$$
T_{S}=T+\left(\frac{\frac{\mu I^{2}}{\Pi D}+\frac{h r V^{2}}{2 C_{p}}-\frac{2}{\Pi} E V W_{E} L_{V}}{h+\sigma n+\frac{2}{\Pi} E V W C_{W}}\right) .
$$

The derivation of (2) is given in appendix $B$, and a more detailed discussion of the terms of heat balance can be found in Makkonen (1984). 


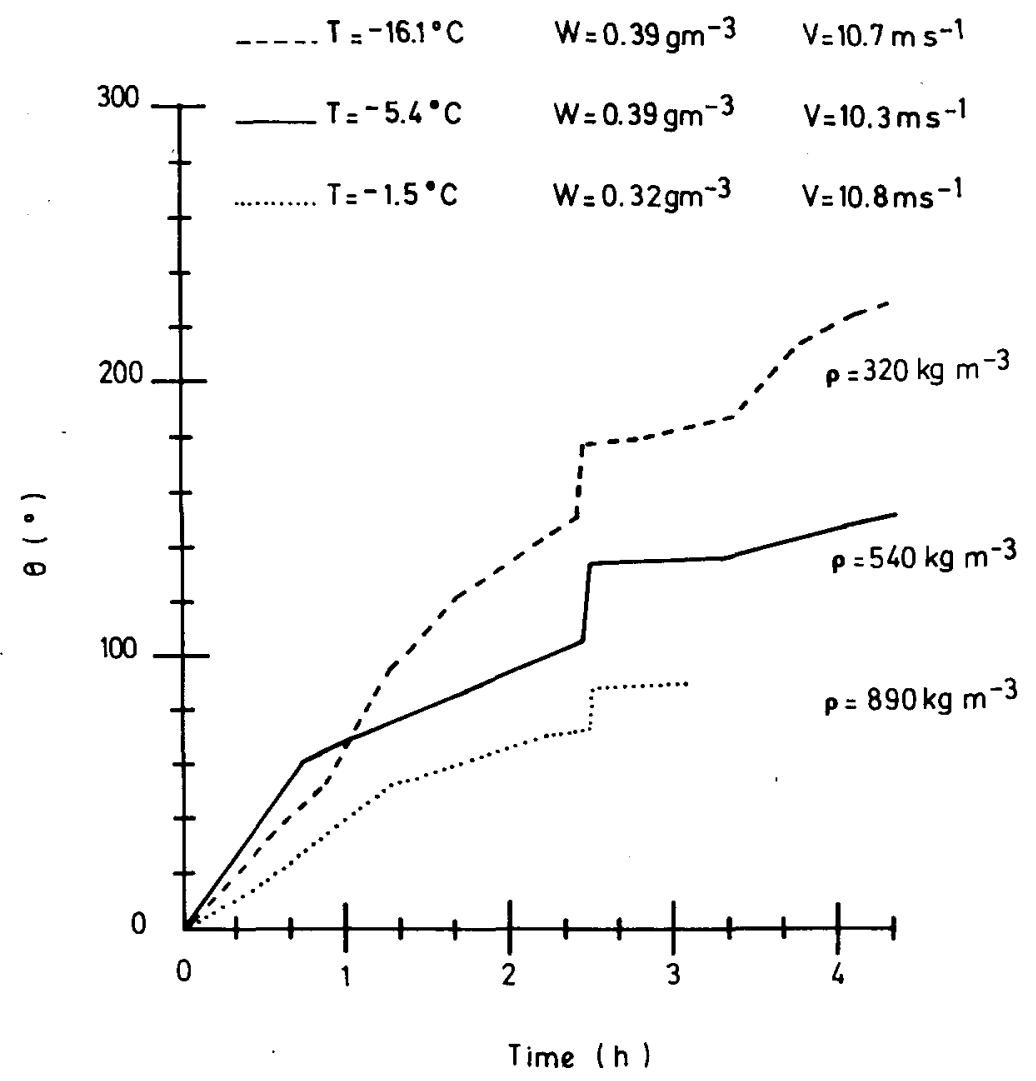

FiG. 10. Angle of rotation of Aster 148 model wire as a function of time for three tests performed at different temperatures (tests 18,7 and 15). The liquid water content and the airspeed are similar. The corresponding measured ice densities are also shown.

In (2), $T$ is the air temperature, $\mu$ the resistance per unit of length of the wire, $I$ the current intensity, $D$ the wire diameter, $h$ the convective heat transfer coefficient, $r$ the wire recovery factor, $V$ the airspeed, $C_{p}$ the specific heat of air at constant pressure, $E$ the total collection efficiency, $W_{E}$ the evaporated liquid water content, $W$ the cloud liquid water content, $L_{V}$ the specific latent heat of vaporization, $\sigma$ the Stefan-Boltzmann constant, $n=8.1 \times 10^{7} \mathrm{~K}^{3}$, and $C_{W}$ the specific heat of water.

The convective heat transfer coefficient $h$ in (2) can be expressed as a function of the overall Nusselt number $\mathrm{Nu}$ :

$$
h=k_{a} \mathrm{Nu} / D,
$$

where $k_{a}$ is the thermal conductivity of air. The following parameterization of $\mathrm{Nu}$ at the stagnation point was chosen according to the results of McComber et al. (1978), Shlichting (1979), and Makkonen (1985):

$$
\mathrm{Nu}=\sqrt{\mathrm{Re}}
$$

with $R e$, the Reynolds number, $\sim 10^{4}$.

As mentioned by Bain and Gayet (1982), we assume that the value of the heat transfer coefficient on the stagnation line is representative of the whole cylinder.
The wire surface temperature can be calculated from (2), then compared to the measured value displayed in Fig. 11 by introducing the measured values of the air temperature, the airspeed, the liquid water content and the equivalent current intensity. The total collection efficiency is obtained by using the theory for a cylinder (the wire is not iced and is assumed to have a circular cross section) and the measured median volume diameter of the cloud droplet spectra.

The calculated (dotted curve) and measured (solid curve) wire surface temperatures, as well as the liquid water content are shown as a function of time in Fig. 12. A good agreement, within $0.5^{\circ} \mathrm{C}$, is observed between the two temperatures which correspond to the accuracy of the surface temperature probe. This good agreement provides a basis for estimation of the current required to prevent the icing of wires.

\section{c. Diagram of current required to prevent the icing of wires}

Assuming that a wire surface temperature of $0^{\circ} \mathrm{C}$ is sufficient to prevent the icing, the current may be ob- 


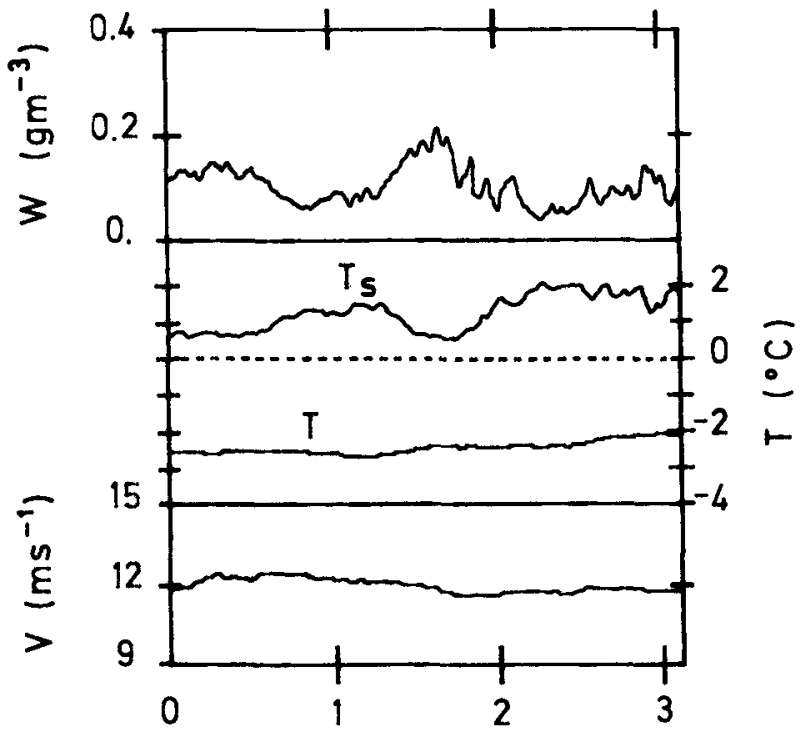

Time (h)

Fig. 11. Example of test which relates to the heating of the Aster 148 model wire. The equivalent current is $425 \mathrm{~A}$. This figure shows the time evolution of the liquid water content $W$; the surface temperature, $T_{S}$, measured at the stagnation line; the air temperature $T$; and the airspeed $V$. Note the anti-correlation between $W$ and $T_{S}$.

tained from (2). We consider a constant value of the median volume diameter of $12 \mu \mathrm{m}$ (mean value observed during the experiment) for the calculation of the total collection efficiency.

Figures $13 \mathrm{a}$ and $\mathrm{b}$ represent the current intensities required to prevent the icing of the Aster 148 and Aster 570 wires, respectively, as a function of the airspeed, for two air temperatures $\left(-5^{\circ}\right.$ and $\left.-10^{\circ} \mathrm{C}\right)$ and three liquid water contents $\left(0.1,0.3\right.$ and $\left.0.5 \mathrm{~g} \mathrm{~m}^{-3}\right)$. For example, a liquid water content of $0.3 \mathrm{~g} \mathrm{~m}^{-3}$, an airspeed of $10 \mathrm{~m} \mathrm{~s}^{-1}$ and an air temperature of $-5^{\circ} \mathrm{C}$ require current intensities of 560 and $1210 \mathrm{~A}$ for the Aster 148 and Aster 570 wires respectively. Furthermore, the examination of the figures leads to the following remarks:

i) For low airspeed $\left(V<4 \mathrm{~m} \mathrm{~s}^{-1}\right)$, and for a given air temperature, the current intensities are identical whatever the liquid water content. Indeed, under these conditions, the cylinder collection efficiency has a very low value (Personne and Gayet, 1984) and the heat losses due to evaporation $Q_{E}$ and to the warming term $Q_{W}$ may be neglected. In this case, the heat balance is mainly governed by the Joule effect heating $Q_{J}$ and by the loss of sensible heat by convection and conduction $Q_{c}$; the other terms $Q_{V}$ and $Q_{s}$ are of one order of magnitude smaller than the $Q_{J}$ and $Q_{C}$ terms (see appendix B).

ii) For medium airspeeds $\left[3-15 \mathrm{~m} \mathrm{~s}^{-1}, T=-5^{\circ} \mathrm{C}\right.$, and the Aster 148 wire for example (Fig. 13a)], the current intensity depends on the liquid water content. In this case, all the impinging liquid water is evaporated.

iii) For an high airspeed $\left[\left(V>16 \mathrm{~m} \mathrm{~s}^{-1}, T=-5^{\circ} \mathrm{C}\right.\right.$, and the Aster 148 wire (Fig. 13a)], the current intensity does not depend upon the liquid water content. In this case, only a fraction of the impinging water is evaporated and the remaining water runs off by gravitational draining.

\section{Conclusions}

With an instrumented wind tunnel for the study of icing on wires, which operates in natural icing conditions, it is possible to perform continuous and accurate measurements of airspeed, temperature and cloud parameters. Sequential measurements of ice deposit characteristics can also be obtained and complemented by photographic records.

This instrumented wind tunnel produces ice accretions with characteristics very similar to those observed on power lines in France. The results are the following:

- The accreted ice was formed all around the wires by wire torsion due to gravitational and aerodynamic forces, and the shape of the ice deposits was not cylindrical even for the longest tests. The ice profiles were usually nonsymmetric with a rough surface and a complex shape mostly characterized by a quasi-flat front surface. These observations confirm those obtained by Makkonen and Stallabrass (1984) in a laboratory wind tunnel.

- The icing rate is strongly dependent upon the increasing of the ice deposit thickness as a function of time. The growth rate increases with the ice front width.

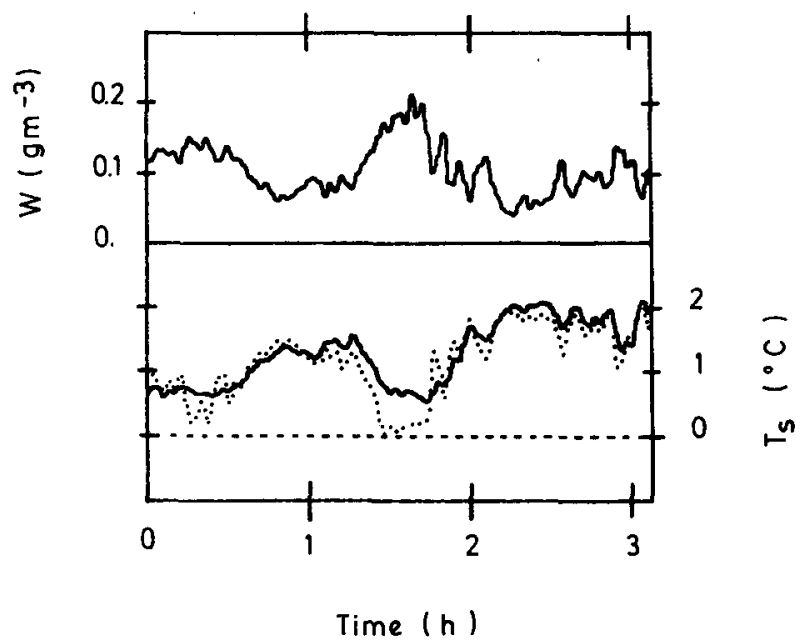

FIG. 12. Time evolution of the liquid water content $W$, the measured surface temperature (solid curve), and the calculated surface temperature (dotted curve) for the test shown in Fig. 11. 

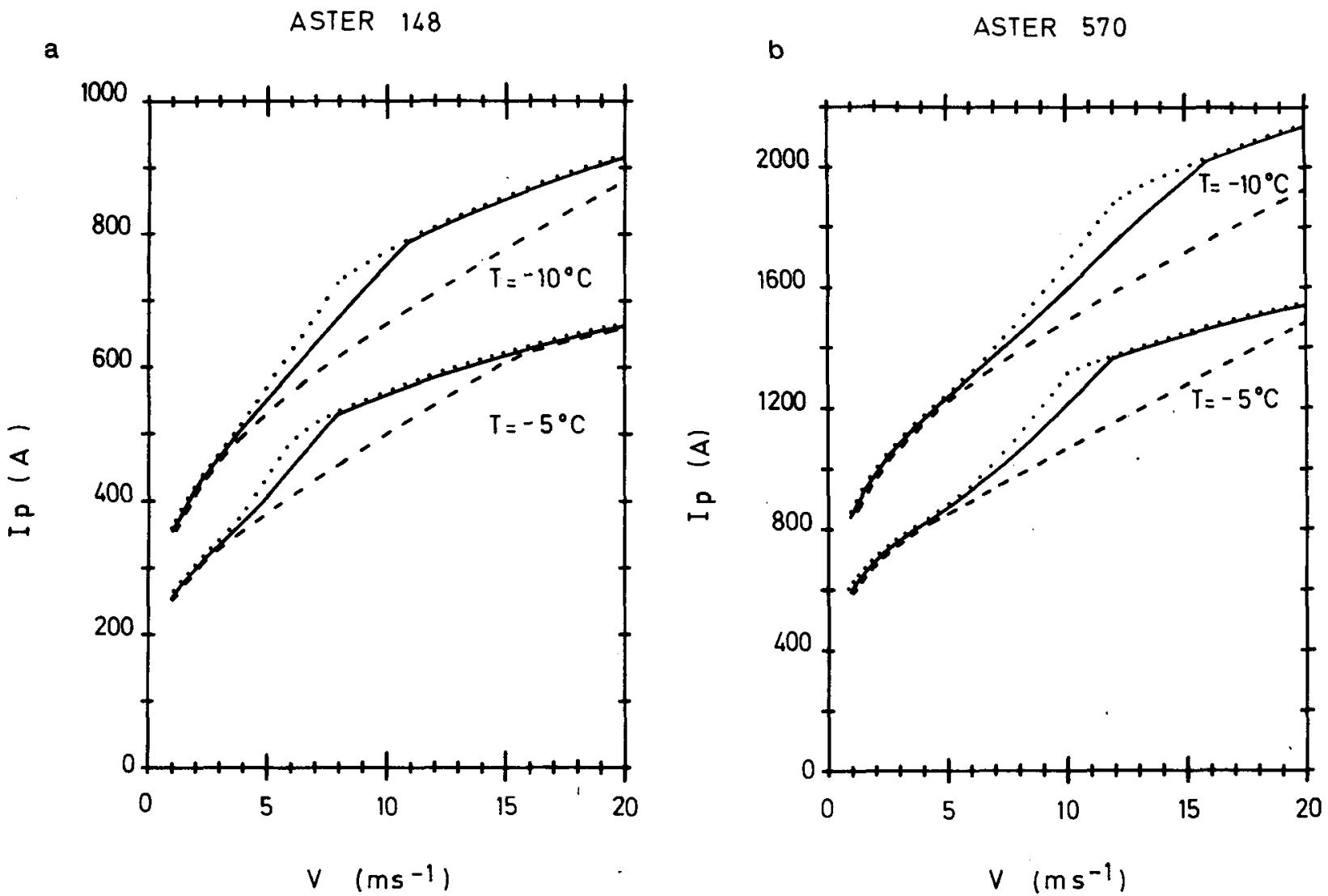

FIG. 13. Current $I_{P}$ required to prevent the icing of Aster 148 (Fig. 13a) and Aster 570 (Fig. 13b) wires as a function of the airspeed, for two air temperatures $\left(-5^{\circ}\right.$ and $-10^{\circ} \mathrm{C}$ ) and three liquid water contents: $0.1 \mathrm{~g} \mathrm{~m}^{-3}$ (dashed curve), $0.3 \mathrm{~g} \mathrm{~m}^{-3}$ (solid curve), and $0.5 \mathrm{~g} \mathrm{~m}^{-3}$ (dotted curve).

- The total collection efficiency defined for the observed ice shapes is small $(0.1)$. The discrepancies between the measured collection efficiencies and those predicted by Langmuir and Blodgett's theory increase with time and consequently with the ice thickness. Furthermore, the variations of the median volume diameter induce variations of the mass growth rate which are smaller than those predicted by the above mentioned theory relative to smooth cylinders. These results point out the difficulties in modeling the detail of ice accretion on wires when the ice deposits present a rough surface and a noncircular profile. Nevertheless, these conclusions only refer to our range of conditions, which were an airspeed about $10 \mathrm{~m} \mathrm{~s}^{-1}$, liquid water content $<0.6 \mathrm{~g} \mathrm{~m}^{-3}$, median volume diameter varying from 8 to $16 \mu \mathrm{m}$, air temperature $<-16^{\circ} \mathrm{C}$, time exposure $<22 \mathrm{~h}$ and ice deposits with diameter less than $6 \mathrm{~cm}$.

- A decrease in the air temperature induces an increase in the angle of rotation and ice growth rates due to a decrease of the ice density.

- The accurate measurements of the wire surface temperature lead to confirmation of the heat balance equation for heated wires.
- An estimation of the current required to prevent the icing of the wires in any icing conditions is proposed.

Acknowledgments. The authors would like to express their appreciation to Professor R. G. Soulage, Dr. H. Isaka and Dr. Y. Pointin for their guidance during this study and Professor Coulman for his comments on the manuscript. They are indebted to Dr. D. Ramond, Director of the Observatoire de Physique du Globe de Clermont-Ferrand, for allowing them to use the $\mathrm{Ob}$ servatory at the summit of Puy de Dôme. Thanks are due to L. Cortès, J.-F. Fournol and M. Soulage for their technical assistance during the experiment, and O. Guillot, S. Bondoux and J. Squarise for preparing the manuscript.

This research was supported by Electricite de France, Direction Etudes et Recherches, Service "Applications de l'Electricité et Environnement", Division "Météorologie Appliquée et Pollution Atmosphérique", service "Matériel Electrique", Division "Lignes Aériennes" under Contract EDF/ADERA n ${ }^{\circ}$ E 30 L29/2E 8026. 
APPENDIX A

\section{Summary of the Characteristics and Results of the Tests Performed in 1985}

TABLE Al. Test summary. Reported in this table are the test number (the numbers in brackets refer to the sequential measurements performed during a given test); $\Delta t$, time exposure; $T$, air temperature; $V$, airspeed; $W$, liquid water content; MVD, median volume diameter; $R$, mass growth rate; $L_{\max }$, ice front width measured at the end of the test; $R /(V W)$, ratio of the mass growth rate of the airspeed and the liquid water content; and $\bar{L}$, ice front width averaged over the interval in which $R$ is calculated.

\begin{tabular}{|c|c|c|c|c|c|c|c|c|c|c|c|c|c|}
\hline \multirow[b]{2}{*}{ Test } & \multirow[b]{2}{*}{$\Delta t$} & \multirow[b]{2}{*}{$\begin{array}{c}T \\
\left({ }^{\circ} \mathrm{C}\right)\end{array}$} & \multirow[b]{2}{*}{$\begin{array}{c}V \\
\left(\mathrm{~m} \mathrm{~s}^{-1}\right)\end{array}$} & \multirow[b]{2}{*}{$\begin{array}{c}W \\
\left(\mathrm{~g} \mathrm{~m}^{-3}\right)\end{array}$} & \multirow[b]{2}{*}{$\begin{array}{c}\text { MVD } \\
(\mu \mathrm{m})\end{array}$} & \multicolumn{4}{|c|}{ ASTER 148 model wire } & \multicolumn{4}{|c|}{ ASTER 570 model wire } \\
\hline & & & & & & $\begin{array}{c}R \\
\left(\mathrm{gm}^{-1} \mathrm{~h}^{-1}\right)\end{array}$ & $\begin{array}{l}L_{\max } \\
(\mathrm{cm})\end{array}$ & $\begin{array}{l}\frac{R}{V W} \\
(\mathrm{~m})\end{array}$ & $\underset{(\mathrm{cm})}{\bar{L}}$ & $\begin{array}{c}R \\
\left(\mathrm{gm}^{-1} \mathrm{~h}^{-1}\right)\end{array}$ & $\begin{array}{l}L_{\max } \\
(\mathrm{cm})\end{array}$ & $\frac{R}{V W}$ & $\underset{(\mathrm{cm})}{\tilde{L}}$ \\
\hline 5 & 12 h $10^{\prime}$ & -4.4 & 8.8 & 0.44 & 16.2 & 39.3 & 3.3 & & & 38.5 & 4.6 & & \\
\hline 6 & 7 h $18^{\prime}$ & -5.4 & 9.2 & 0.59 & 14.7 & 51.6 & 2.9 & & & 58.4 & 4.2 & & \\
\hline 7 & 6 h $49^{\prime}$ & -5.4 & 10.3 & 0.39 & 11.8 & 37.0 & 2.7 & & & 43.0 & 4.1 & & \\
\hline 8 & 18 h $40^{\prime}$ & -7.5 & 10.6 & 0.26 & 10.3 & 45.1 & 6.8 & & & 44.4 & 6.6 & & \\
\hline 9 & 2 h $14^{\prime}$ & -8.7 & 11.4 & 0.14 & 9.1 & 15.3 & 2.0 & 0.00266 & 1.8 & 18.3 & 3.3 & 0.00318 & 3.2 \\
\hline 13 & 15 h $30^{\prime}$ & -10.7 & 11.7 & 0.25 & 13.0 & 38.8 & 4.6 & & & 40.0 & 5.0 & & \\
\hline 14 & 4 h $45^{\prime}$ & -12.9 & 11.2 & 0.17 & 10.4 & 19.3 & 2.2 & & & 23.6 & 3.8 & & \\
\hline $14(1)$ & 2 h $02^{\prime}$ & -12.4 & 11.5 & 0.15 & 9.9 & 15.7 & & 0.00254 & 1.7 & 23.0 & & 0.00371 & 3.2 \\
\hline $14(2)$ & $1 \mathrm{~h} 58^{\prime}$ & -13.3 & 10.9 & 0.23 & 11.4 & 25.4 & & 0.00283 & 1.9 & 27.2 & & 0.00303 & 3.5 \\
\hline $14(3)$ & $0 \mathrm{~h} 45^{\prime}$ & -13.2 & 11.2 & 0.15 & 9.4 & 18.2 & & 0.00299 & 2.1 & 21.7 & & 0.00357 & 3.7 \\
\hline 15 & 7 h $24^{\prime}$ & -16.1 & 10.7 & 0.32 & 13.5 & 45.1 & 3.5 & & & 41.2 & 4.4 & & \\
\hline $15(1)$ & 2 h $05^{\prime}$ & -15.6 & 11.0 & 0.38 & 13.6 & 44.6 & & 0.00298 & 1.8 & 50.7 & & 0.00338 & 3.3 \\
\hline $15(2)$ & $2 \mathrm{~h} 00^{\prime}$ & -15.7 & 10.5 & 0.41 & 14.4 & 61.4 & & 0.00398 & 2.3 & 66.9 & & 0.00434 & 3.7 \\
\hline $15(3)$ & 1 h $58^{\prime}$ & -16.3 & 10.7 & 0.21 & 12.4 & 33.5 & & 0.00415 & 3.0 & 33.1 & & 0.00410 & 4.1 \\
\hline $15(4)$ & $1 \mathrm{~h} 21^{\prime}$ & -16.8 & 10.4 & 0.30 & 13.8 & 46.3 & & 0.00411 & 3.4 & 48.4 & & 0.00423 & 4.3 \\
\hline 16 & 5 h $22^{\prime}$ & -0.9 & 11.4 & 0.13 & 8.9 & & & & & 13.9 & 3.1 & & \\
\hline 17 & $2 \mathrm{~h} 55^{\prime}$ & -3.8 & 11.5 & 0.13 & 7.3 & & & & & 20.3 & 3.1 & 0.00377 & 3.1 \\
\hline 18 & $3 \mathrm{~h} \mathrm{04}^{\prime}$ & -1.5 & 10.8 & 0.32 & 13.6 & 23.6 & 1.6 & 0.00190 & 1.6 & 39.1 & 3.1 & 0.00314 & 3.1 \\
\hline 19 & 17 h $28^{\prime}$ & -2.3 & 10.6 & 0.39 & 15.3 & 45.7 & 4.0 & & & & & & \\
\hline 20 & $2 \mathrm{~h} 53^{\prime}$ & -1.8 & 11.6 & 0.24 & 13.3 & 38.9 & & & & & & & \\
\hline 22 & 7 h 45' & -4.3 & 11.2 & 0.36 & 15.7 & & & & & 55.8 & & & \\
\hline 27 & 22 h $22^{\prime}$ & -3.3 & 11.0 & 0.41 & 12.4 & & 5.8 & & & & & & \\
\hline $27(1)$ & $1 \mathrm{~h} 59^{\prime}$ & -3.7 & 11.2 & 0.40 & 12.6 & 33.4 & & 0.00207 & 1.6 & & & & \\
\hline $27(2)$ & $1 \mathrm{~h} 58^{\prime}$ & -3.7 & 11.6 & 0.48 & 13.8 & 49.1 & & 0.00244 & 1.9 & & & & \\
\hline $27(3)$ & $1 \mathrm{~h} 59^{\prime}$ & -3.6 & 10.4 & 0.72 & 15.7 & 90.6 & & 0.00336 & 2.4 & & & & \\
\hline $27(4)$ & $2 \mathrm{~h} 02^{\prime}$ & -3.8 & 10.2 & 0.64 & 14.9 & 85.1 & & 0.00361 & 2.8 & & & & \\
\hline $27(5)$ & $2 \mathrm{~h} \mathrm{O1^{ \prime }}$ & -3.9 & 11.0 & 0.44 & 13.1 & 59.3 & & 0.00341 & 3.1 & & & & \\
\hline $27(6)$ & $1 \mathrm{~h} 59^{\prime}$ & -3.5 & 10.8 & 0.37 & 12.0 & 53.9 & & 0.00374 & 3.5 & & & & \\
\hline $27(7)$ & $2 \mathrm{~h} 00^{\prime}$ & -3.2 & 11.0 & 0.42 & 12.9 & 67.4 & & 0.00407 & 4.0 & & & & \\
\hline $27(8)$ & $2 \mathrm{~h} \mathrm{Ol}^{\prime}$ & -3.2 & 10.6 & 0.44 & 12.9 & 80.7 & & 0.00482 & 4.7 & & & & \\
\hline 27 (9) & 2 h $39^{\prime}$ & -3.0 & 11.1 & 0.38 & 12.4 & 96.5 & & 0.00636 & 5.3 & & & & \\
\hline $27(10)$ & 3 h $44^{\prime}$ & -2.6 & 11.9 & 0.11 & 7.9 & 26.3 & & 0.00557 & 5.7 & & & & \\
\hline
\end{tabular}

\section{APPENDIX B}

\section{Derivation of the Heat Balance Equations (2)}

The steady state heat balance equation that is assumed to describe the thermodynamics at the surface of a heated wire which is subject to icing may be written formally as

$$
\begin{aligned}
Q_{F}+Q_{J}+Q_{V}+Q_{K} \\
\quad=Q_{C}+Q_{E}+Q_{W}+Q_{I}+Q_{S}+Q_{A}
\end{aligned}
$$

where

$Q_{F} \quad$ latent heat flux released during freezing

$Q$, heat flux due to heating of wire by Joule effect

$Q_{V}$ heat flux due to aerodynamic heating

$Q_{K}$ heat flux due to the kinetic energy of the droplets and ice crystals
$Q_{C} \quad$ loss of sensible heat between the wire and the airstream by conduction and convection

$Q_{E}$ heat loss due to evaporation

$Q_{W}$ heat loss in warming the impinging water to the surface temperature

$Q_{l} \quad$ heat loss in warming the impinging ice crystals to the surface temperature

$Q_{S}$ heat loss due to radiation

$Q_{A}$ heat loss due to internal conduction on the ends of the model wire.

If the surface temperature is greater than $0^{\circ} \mathrm{C}$, the droplets do not freeze on the wire, and the term $Q_{F}$ in (B1) has consequently a zero value. Besides, the terms $Q_{K}, Q_{I}$ and $Q_{A}$ are very small in regards to the magnitude of the other ones due to the conditions observed during our experiment and may be neglected. 
The other terms in (B1) can be parameterized as shown in (B2) to (B7) for unit area of wire:

$$
Q_{J}=\mu I^{2} /(\pi D),
$$

where $I$ is the current intensity, $\mu$ the resistance per unit of length and $D$ the diameter of wire;

$$
Q_{V}=h r V^{2} /\left(2 C_{p}\right)
$$

where $h$ is the heat transfer coefficient, $r$ the recovery factor which is assumed equal to $0.9, V$ the air velocity and $C_{p}$ the specific heat of air at constant pressure;

$$
Q_{C}=h\left(T_{S}-T\right)
$$

where $T_{S}$ and $T$ are, respectively, the surface temperature and the air temperature;

$$
Q_{W}=(2 / \pi) E V W C_{W}\left(T_{S}-T\right)
$$

where $E$ is the total collection efficiency calculated from the median volume diameter using the parameterization of Lozowski et al. (1983), $W$ the liquid water content and $C_{W}$ the specific heat of water;

$$
Q_{S}=\sigma n\left(T_{S}-T\right)
$$

where $\sigma$ is the Stefan-Boltzmann constant and $n=8.1$ $\times 10^{7} \mathrm{~K}^{3}$ near $0^{\circ} \mathrm{C}$;

$$
Q_{E}=(2 / \pi) E V W_{E} L_{V}
$$

where $L_{V}$ is the latent heat of evaporation and $W_{E}$ is the liquid water which is evaporated at the surface of the wire. When the cloud liquid water content $W$ is low, all the impinging water is evaporated $\left(W_{E}=W\right)$. When the liquid water content is high, the surface of the wire becomes wet. In this case, only a fraction of the impinging water is evaporated $\left(W_{E}<W\right)$ and the remaining water leaves the wire by gravitational draining. The point of surface saturation is reached when the rate of water impingement on the wire just equals the maximum possible rate of evaporation from the wire. The relationship between these two rates can be derived as follows (Neel, 1973):

$$
(2 / \pi) E V W=0.622 h\left[e\left(T_{S}\right)-e(T)\right] /\left(P C_{p}\right)
$$

where $P$ is the pressure and $e(T)$ the saturation vapor pressure of moist air at temperature $T$. Consequently, beyond this point, the liquid water content which is evaporated can be expressed as follows:

$$
W_{E}=\pi 0.622 h\left[e\left(T_{S}\right)-e(T)\right] /\left(2 E V P C_{p}\right) .
$$

Finally, Eq. (B1) may be written for a heated and non-icing wire:

$$
\begin{aligned}
& \left(T_{S}-T\right)\left[h+\sigma n+(2 / \pi) E V W C_{W}\right] \\
& \quad=\mu I^{2} /(\pi D)+h r V^{2} /\left(2 C_{p}\right)-(2 / \pi) E V W_{E} L_{V}
\end{aligned}
$$

\section{REFERENCES}

Ackley, S. F., and M. K. Templeton, 1979: Computer modeling of atmospheric ice accretion. CRREL, Rep. $79.4,36 \mathrm{pp}$.

Bain, M., and J. F. Gayet, 1982: Aircraft measurements of icing in supercooled and water droplet/ice crystal clouds. J. Appl. Meteor., 5, 631-641.

Brownscombe, J. L., and J. Hallet, 1967: Experimental and field studies of precipitation particles formed by the freezing of supercooled water. Quart. J. Roy. Meteor., 93, 455-473.

Crowe, C. T., J. A. Nicholls and R. B. Morrison, 1963: Drag coefficients of inert and burning particles accelerating in gas streams. Ninth Int. Sympos. on Combustion, Academic Press, 395-405.

Dye, E. J., and D. Baumgardner, 1984: Evaluation of the forward scattering spectrometer probe. Part I: Electronic and optical studies. J. Atmos. Oceanic Technol, 1, 329-344.

Gayet, J. F., 1986: Calibration of Johnson-William and PMS ASSP probes in a wind tunnel. J. Atmos. Oceanic Technol, , 3, 381390.

Gland, H., 1985: Givre, verglas, neige collante: nature des phénomènes et situations météorologiques correspondantes. Journée d'études de la SEE sur les lignes aériennes face à l'environnement climatique, Gif-sur-Yvette, 5-11.

Imai, I., 1953: Studies of ice accretion. Res. Snow Ice, A, 35-44 (in Japanese).

Langmuir, I., and K. B. Blodgett, 1946: A mathematical investigation of water droplet trajectories. Tech. Rep. 5418, USAAF, 65 pp.

Lozowski, E. P., J. R. Stallabrass and P. F. Hearty, 1983: The icing of an unheated, nonrotating cylinder. Part I: A simulation model. J. Climate Appl. Meteor., 22, 2053-2062.

Macklin, W. C., 1962: The density and structure of ice formed by accretion. Quart. J. Roy. Meteor. Soc., 88, 30-50.

Makkonen, L., 1984: Modeling of ice accretion on wires. J. Climate Appl. Meteor., 23, 929-939.

, 1985: Heat transfer and icing of a rough cylinder. Cold Regions Sci. Tech., 10, 105-116.

- and J. R. Stallabrass, 1984: Ice accretion on cylinders and wires. NRCC Report, TR-LT-005.

McComber, P., and G. Touzot, 1981: Calculation of the impingement of cloud droplets in a cylinder by the finite-element method. $J$. Atmos. Sci., 38, 1027-1036.

- and J. W. Govoni, 1985: An analysis of selected ice accretion measurements on a wire at Mt. Washington. Proc. of the Eastern Snow Conference, Montreal.

- D. D. Nguyen and J. Druez, 1978: Prévention par chauffage de la formation de givre ou de verglas sur les conducteurs cylindriques et toronnés. Can. Elec. Eng. J., 3, n² 2 .

Neel, C. B., 1973: Measurement of cloud liquid water content with a heated wire. Proc. 19th Int. Aerospace Symp., Vol. 19, B. Washburn, Ed., 30 pp.

Personne, P., and J. F. Gayet, 1984: Êtude théorique et étude expérimentale en soufflerie du phénomène d'accrétion de givre sur les lignes électriques aériennes. J. Rech. Atmos., 18, 263279.

Schlichting, H., 1979: Boundary-Layer Theory. McGraw-Hill, New York, $817 \mathrm{pp}$. 